\title{
La jerga propia precisa: propuesta para una taxonomia detallada de la terminología epónima y deónima
}

\author{
The proper and precise jargon: a proposal for a detailed taxonomy \\ of eponymic and derived eponymic terminology
}

\author{
Juan José Calvo García de Leonardo
}

Universitat de València. Estudi General (UVEG). calvojj@uv.es

Recibido: 30.01.2019. Aceptado: 14.07.2019

Resumen: El traductor científico-técnico acude a los glosarios y no a la onomástica para resolver dilemas puntuales. Y si bien es cierto que no hay una correspondencia científicamente reglada entre el modo de traducir y la naturaleza del terminus technicus, también lo es que -al menos que sepamos- no se ha intentado establecer ninguna catalogación al efecto en primer lugar para, en su momento, relacionar ambos. El presente trabajo resulta de una investigación que se encuentra a término, ya presentada (Calvo, 2014a, 2014b, 2015, 2017a, 2017b, 2018) en algunas de sus facetas. Aquí proponemos y ejemplificamos una taxonomía del término técnico epónimo o deónimo, válida para sus conjuntos principales (geónimos y antropónimos, además los subsidiarios ctisónimos: los nombres de productos, incluidos los nombres de marcas y de obras de arte) y, emulando la taxonomía de las ciencias biológicas, estipulamos hasta dieciséis especificadores, en orden descendente y ramificado, para delimitar, con la mayor precisión posible, las características lingüísticas, referenciales y culturales -a las que se añade el modo de traslado, de traducción empíricamente observable- para un solo término específico o para la agrupación de sus pares.

Palabras clave: terminología; onomástica; eponimia y deonimia; taxonomia; traducción.

\footnotetext{
Abstract: The translator of scientific and technical texts resorts to glossaries and not to onomastics to solve eventual dilemmas. And while it is a fact that there is no scientifically-ruled correspondence between the way we translate and the nature of the terminus technicus, it is also true - at least as far as we know- that there have been no attempts to first categorize and, eventually, relate them. The present paper results from the end-phase of a research already made public in some of its facets (Calvo, 2014a, 2014b, 2015, 2017a, 2017b, 2018). What we here propose and exemplify is a taxonomy

》 Calvo García de Leonardo, Juan José. 2019. "La jerga propia precisa: propuesta para una taxonomia detallada de la terminología epónima y deónima". Quaderns de Filologia: Estudis Lingüistics XXIV: 93-117. doi: 10.7203/QF.24.16301
} 
of eponyms and derived eponyms valid for its main sets (geonyms and anthroponyms, plus the subsidiary ctisonyms: product names, including brand names and names of works of art) in which, imitating the taxonomy of biological sciences, we stipulate up to sixteen top to bottom branching specifiers in order to pinpoint, as much as possible, the linguistic, referencial and cultural characteristics - plus the empirically observable mode of translation- for only one specific term or its peer grouping.

Keywords: terminology; onomastics; eponymy and derived eponymy; taxonomy; translation. 


\section{Introducción}

La ciencia persigue la acribia, la taxonomía y la onomástica, como auxiliares suyas, también. Para la Escuela de Praga, la función del lenguaje científico-técnico reside en suministrar un repertorio de signos que permita, del modo más preciso y económico, el entendimiento en relación a un campo referencial y objetual específico (Fluck, 1976: 12 s.). El tecnolecto se puede entender ${ }^{1}$, por tanto, como la representación verbal de objetos que existen de manera independiente de las lenguas naturales que los expresan y, en este sentido, nos retrotraerá a los modelos primigenios de la semántica: a la onomástica del nominibus suis (Gen. 19-20) y al principio de physei en el Crátilo.

Nosotros atendemos los dos aspectos de la fijación terminológica: la innovación, proponiendo terminología neologizante y la normalización, precisando con mayor exactitud la ya existente. A nuestros efectos, la organización internacional más pertinente es el ICOS (International Council of Onomastic Sciences), que tiene listados un total de 18 especificaciones en -ónimo, a las que hay que añadir alónimo, deónimo, endónimo, epónimo, exónimo y pseudónimo. Nuestra propuesta taxonómica suma 333 hasta la fecha, excluidos estos 6 últimos, pero aquí vamos a presentar algo mucho más abstracto.

A modo de comparación: la definición clásica, la que presenta Aristóteles, requiere de un definiendum, un definitor y un definiens que, a su vez, puede especificarse más todavía, mediante el genus proximus y la differentia specifica (Roelke, 1999: 54 s.). Por ejemplo, en lingüística, diríamos que «un préstamo (definiendum) es (definitor) un elemento lingüístico extranjero (definiens: genus proximus), de carácter fonético, gramatical, léxico, estilístico, pragmático o cultural (definiens: differentia specifica)». Este modelo conlleva estratificación y jerarquizacíon, con un diseño 'arbolado' de hiperónimos e hipónimos y algo parecido es lo que aquí acometemos. Presentamos, en concreto, una jerarquización taxonómica, tanto del término técnico epónimo o deónimo como de los nombres propios de obras materiales e intelectuales y artísticas que deriven de o contengan geónimos o antropónimos, puesto que son,

\footnotetext{
${ }^{1}$ Con todas las limitaciones inherentes al hecho de que un mismo terminus technicus pueda tener distintos significados y referentes en los diferentes campos de la ciencia y de la tecnología e incluso dentro de una misma especialidad, como nos recuerdan, una y otra vez, Cabré (1993: 214 s.) o Alcaraz (2000: 49 y passim).
} 
referencialmente hablando, homoiousiacos u homoousiacos: de naturaleza similar o de naturaleza idéntica. Para ello, proponemos una reformulación de la nomenclatura binomial de las ciencias biológicas con un taxón doble que aquí solemos introducir mediando la barra alternativa (/): un adjetivo latino (o latinizante) en -al y uno griego (o helenizante) en -ónimo ... lo que nos permite reutilizarlo como substantivo. Nuestra taxonomía resulta válida para tres 'Cuerpos' principales: los Geónimos y los Antropónimos con valor de absolutos, más el Cuerpo subsidiario de los Ctisónimos ${ }^{2}$ : los nombres de productos y de marcas y de las obras del intelecto, de la arquitectura o del arte. Además, emulando la catalogación de las ciencias biológicas, estipulamos hasta dieciséis especificadores en orden descendente -aunque no siempre concurran los dieciséis al completo- para delimitar, con la mayor precisión posible, las características lingüísticas, referenciales y culturales de un término científico-técnico/nombre de producto o agrupación de pares. A ello sumamos el modo en que se ha trasladado el término: la traducción empíricamente observable. Tanto para la taxonomía como para la traslación, se ha recurrido a diccionarios monolingües, bilingües y especializados, a glosarios específicos y a enciclopedias y compendios, historias del arte literatura o cine $\mathrm{y}$, -sobre todo en lo que se refiere a los nombres propios, aunque también a algunos contrastes multilingües de terminología científico-técnica- a las páginas pertinentes de la Wikipedia (que no deberían ser sospechosas de mera traducción del inglés en lo que a la nomenclatura estricta se refiere) y a otras referencias en línea. Se trata, por lo tanto, de una propuesta doble. Por un lado, es estática e intralingüística en busca de la más exacta identificación. Por otro, es dinámica e interlingüística, al ofrecer su correlato bi- o plurilingüe en traducción, si lo hubiera.

Nuestro corpus es un glosario bilingüe, principal, aunque no exclusivamente, inglés-español ${ }^{3}$, espigado a mano y que consta de, al menos, 2370 geónimos y 1908 antropónimos (hay que considerar las variantes alógrafas tan comunes en inglés), a los que sumar los cti-

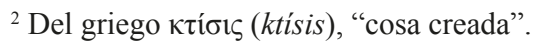

${ }^{3}$ Sobre todo en lo que refiere a la terminología científico-técnica, no en lo que respecta a la catalogación de los nombres de productos, de marcas y de obras intelectuales y artísticas, donde se amplía la gama a las principales lenguas nacionales de Europa y fuera de ella, si resultaran convenientes para un contraste específico.
} 
sónimos ('fabrales'/‘tecnónimos'4; 'comoditales'/“crematónimos'5 y creacionales'/“ergónimos”'), que se ejemplificarán más adelante. Además se ha elaborado un glosario autónomo, de unos 2500 títulos cinematográficos -también subdividido en geónimos, antropónimos y ctisónimos-correspondientes a los cien primeros años del séptimo arte ${ }^{7}$.

\section{Catalogación de diferenciadores}

\subsection{Jerarquización taxonómica}

Emulando, como decíamos, los clodos, nodos y taxones de la catalogación biológica ${ }^{8}$, nuestra taxonomía se jerarquiza en hasta 10 niveles básicos (más otros 6 facultativos) por orden de creciente precisión que, al revés de lo que ocurre con las ciencias de los seres vivos no son constantes en todos los Cuerpos: la División de los geónimos 'estatales'/'polismatónimos' es la única donde concurren las diez categorías principales.

Por debajo del Cuerpo (que equivaldría, mutatis mutandis, al Reino de la taxonomía biológica), proponemos los siguientes grados de precisión, encolumnando los nombres de los especificadores respectivos:

\footnotetext{
${ }^{4}$ Del griego $\tau \varepsilon ́ \chi v \eta(t e ́ c h n \bar{e})$, “arte”, "artesanía”.

${ }^{5}$ Del griego $\chi \rho \eta \mu \alpha$ (chrēma), "riqueza".

${ }^{6}$ Del griego ع̋ $\rho \gamma o v$ (érgon), "obra”.

${ }^{7}$ Estos son los tres cuerpos referenciales físicos. Asociables a la dinámica de la traducción y sus aspectos, tenemos otros tres que no cabían aquí: el glosario epónimo/deónimo según el modo de traslación, el glosario epónimo/déonimo según la gradación (valoración neutra, apreciativa o despreciativa, posibles cambios en el ámbito geográfico, diafásico y diastrático) y el glosario epónimo/déonimo según el grado de denotación.

${ }^{8}$ Con número diverso de categorías, según elijamos un modelo u otro. Por ejemplo, en la taxonomía tradicional, el homo sapiens ocupa el sexto lugar por debajo del Reino animalia y, en una de las actuales, el homo sapiens sapiens se sitúa en la vigésimoquinta especificación, la Subespecie, por debajo de ese mismo Reino.
} 
CUERPO

D E N O M I N A C I Ó N

CUERPO GEÓNIMOS ANTROPÓNIMOS CTISÓNIMOS

C O M P O S I C I Ó N

(unimembre, bimembre, plurimembre)

\begin{tabular}{|c|c|c|c|}
\hline DIVISIÓN & plasmación & apelación & producción \\
\hline SUBDIVISIÓN & filiación & consideración & corporación \\
\hline GRUPO & alocación & alusión & sectorización \\
\hline SUBGRUPO & ubicación & extensión & vección \\
\hline SECCIÓN & concreción & articulación & presentación \\
\hline SUBSECCION & focalización & ligazón & difusión \\
\hline APARTADO & acotación & tradición & realización \\
\hline SUBAPARTADO & particularización & & \\
\hline ENTRADA & individuación & & \\
\hline SUBENTRADA & vehiculación & & \\
\hline & $\begin{array}{l}\text { (polismatónima } \\
\text { solamente) }\end{array}$ & & \\
\hline
\end{tabular}

\subsection{Diferenciadores comunes a los tres Cuerpos}

Los tres Cuerpos comparten tres diferenciadores: los estáticos de 'denominación' y de 'composición' y el dinámico de ‘traslación' de procedimiento documentado (o propuesto) de traducción.

La 'denominación' identifica el Cuerpo al que pertenece el término: geónimo, antropónimo o ctisónimo. La ‘composición' lo describirá como 'unimembre'/‘monocolonal' (p. ej. sky o skycrane), 'bimembre'/'dicolonal' (p. ej. sky marker) o 'plurimembre'/'policolonal' (sintagmas complejos como sky wave curve o Boston Consulting Group matrix; con sujeto unido por cópula como York and Antwerp rules; y los articulados mediante genitivo sajón como California cat's eye o mediante la preposición of, como Royal dog of Egypt).

El tercer diferenciador común, el apendicular de la 'traslación', nos revela si es a) 'integral' (apropiando el término de la lengua de origen mediante adopción como yapok o mediante adaptación, como el cos- 
mographer y cosmógrafo); b) 'tropical' ('triangulando' (Calvo, 2017a), el 'translema' (Roganova, 1971, en Vidal Claramonte, 1995: 30 s.; vid también Santoyo, 1986) de origen y de meta con su referente); c) 'substitucional' (cambiando el translema por otro', como infernal stone y nitrato de plata); d) 'agregacional' (añadiendo lemas como japan y barniz del Japón); e) 'obvial' (suprimiendo una parte del término o translema, como ocurre con el equipo de fútbol Hamburger S.V. y Hamburgo o Welsh mountain pony y poni galés) o f) 'eclipsal' (si no existe propuesta de traducción en la lengua meta, como scuppernong o sky diving).

En este último caso, el 'eclipsal', se habrá de recurrir a la apropiación (adopción/adaptación) o algún tipo de glosa, de perífrasis explicativa que, además de alambicada, no siempre resulta ni fácil ni útil. Por lo demás, los diferenciadores de traslación pueden darse de manera absoluta -con los términos unimembres, por ejemplo- o, más comúnmente, combinados entre sí (Calvo, 2014a: 34 s.).

\subsection{Diferenciadores especificos}

\subsubsection{Diferenciadores específicos del Primer Cuerpo, el que se} desprende de la localización o la demarcación: los geónimos

El Cuerpo de los Geónimos se parte en tres Divisiones que son modos de plasmación: los 'esenciales'/‘usiónimos' como celestial axis ${ }^{10}$, los 'estatales'/ polismatónimos' como English powder ${ }^{11}$ y los 'colegiales'/'silogónimos' como tuxedo ${ }^{12}$. Dentro de cada uno de ellos, nuestra propuesta subespecifica nueve diferenciadores adicionales: 'filiación', ‘alocación'13, ‘ubicación', ‘concreción', ‘focalización', ‘acotación’, ‘particularización’, ‘individuación’ y ‘vehiculación’.

\footnotetext{
${ }^{9}$ Incluida la 'substitución cultural', como ocurre Elysian y elíseo (que no elisíano) ambos originalmente griegos y parte de la herencia común para ambas culturas, donde el traductor recurrirá 'verticalmente' a su propia tradición y no dependerá 'horizontalmente' de la forma del término en la L1, como aquí el inglés.

${ }^{10}$ Del griego ov̉oía (oúsía), "naturaleza, esencia".

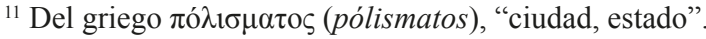

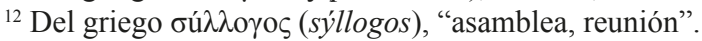

${ }^{13}$ Permítasenos el anglicismo, adaptando allocation.
} 


\subsubsection{Diferenciadores específicos del Segundo Cuerpo, el que se} desprende de la nominación: los antropónimos

El Cuerpo de los antropónimos es el más sencillo, pues solamente cuenta con siete diferenciadores específicos: 'apelación', 'consideración', ‘alusión', ‘extensión', 'articulación', ‘ligazón’ y ‘tradición'.

\subsubsection{Diferenciadores específicos del Tercer Cuerpo el de} la producción o invención: los ctisónimos

Por contra, el Cuerpo subordinado de los ctisónimos es el más complejo de los tres, puesto que, a sus especificadores propios ('producción', 'sectorización', 'vección', 'presentación', 'difusión' y 'realización'), hay que añadir, en su caso, los correspondientes a la referenciación según sea geónima o antropónima.

\section{Ejemplificación de los diferenciadores específicos}

\subsection{Los diferenciadores especificos geónimos ejemplificados}

Los diferenciadores geónimos son comunes a las tres Divisiones que lo componen, los 'esenciales', los 'estatales' y los 'colegiales', si bien ésta última añade el diferenciador de 'tradición'. Por razones de espacio (¡la mera estructura esquemática de los tres Cuerpos suma 45 páginas!) se presenta una ejemplificación reducida ${ }^{14}$.

\subsubsection{Los diferenciadores específicos geónimos}

\section{FILIACIÓN}

Para los geónimos 'esenciales', el primer especificador la Subdivisión de la 'filiación', que se divide en dos: la 'sobrenatural'/'metafisiónima' (con las localizaciones metafísicas de la mitología como Harlequin (cf. Helle + kin «estirpe infernal») o de la religión, como paradise shelduck) y la 'natural'/‘fisiónima ${ }^{15}$ que recoge los referentes de la geografía fí-

\footnotetext{
${ }^{14}$ En Calvo (2014a: 35-37), presentábamos una primera propuesta taxonómica para los geónimos estatales.

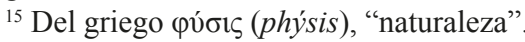


sica: estrellas ('estelariales'/'asterónimos'), planetas (errantestelariales '/'planetónimos') y satélites ('satelitales/‘acolitónimos') que ejemplificamos más abajo.

\section{ALOCACIÓN}

Para la filiación 'sobrenatural' hay cuatro Grupos: las alocaciones 'celestial'/‘elisiónima' (p. ej. el Edén o la vox céleste en el órgano), 'purgatorial'/'catarsónima' (el Purgatorio), 'fimbrial'/'lomónima' (Limbo) e 'infernal'/‘tartarónima' (p. ej. Hell, pero también términos técnicos como hell sheave).

La filiación 'natural' se divide en dos Grupos: las alocaciones 'universal'/'empirónima' (p. ej. Cosmotron o el sintagma celestial equator) y 'terrenal'/‘gayónima', que agrupa referentes del planeta Tierra y que podríamos considerar ya geónimos auténticos.

\section{UBICACIÓN}

Las alocaciones de la filiación 'sobrenatural' dejan de subdividirse.

La alocación 'universal' se subdivide en cuatro Subgrupos: las ubicaciones 'espacial'/'cosmónima' (p. ej. skyshine o sky blueness stu$d y$ ), 'estelarial'/'asterónima' (p. ej. sunstone), 'errantestelarial'/'pla netónima'16 (p. ej. saturnism, Mars-centered o earth orbit insertion), y 'satelital'/‘acolitónimo' (p. ej. selenium, moonflower o moon blindness).

La alocación 'terrenal' se subdivide en seis Subgrupos, en 'ubicaciones' que son meros nodos de sus respectivas 'concreciones': 'global'/‘esferónima' para el globo terrestre, 'flatual'/'anemónima' para los vientos, 'acual'/‘hidrónima'para las aguas, 'mundial'/'ecumenónima' la de las grandes masas terrestres, 'telustral'/'orónima' la de los montes y 'vegetal'/‘fitónima' la de las plantas, que ejemplificamos inmediatamente.

\section{CONCRECIÓN}

El Subgrupo Primero, la ubicación 'global' se perfila en cuatro Secciones: las 'concreciones': 'cardinal'/'axónima' (p. ej. Northern crown, Southern silky oak, East ice o Western hemlock), 'dimidiglobal'/'hemisferónima' (con Southern hemisphere beech como

\footnotetext{
${ }^{16}$ Del latín stella errans, "planeta" (literalmente "estrella errante").
} 
único ejemplo), 'fascial'/'zoniónima' con referencia a los trópicos y similares (p. ej. Arctic char o Equatorial cylindrical orthomorphic projection) y 'areal'/'mecónima' en referencia a una zona geográfica (p. ej. el término textil Levantine o el fitónimo Caribee bark).

El Subgrupo Segundo, la ubicación 'flatual', se ramifica en tres Secciones: la concreción 'turbinal'/'kataigisónima', con los nombres propios asignados a los huracanes (p. ej. Katrina o Mitch), la 'vental'/'eoliónima' con los nombres de vientos (p. ej. mistral o los Westerlies y Easterlies) y la 'aural'/'pneumatónima' de las brisas (p. ej. Freemantle doctor australiano).

El Subgrupo Tercero, la ubicación 'acual' desemboca en nueve Secciones: las concreciones 'maremagnal'/'oceanónima' de los nombres de los océanos o relacionados con ellos (p. ej. Pacific wal$n u t$ ), 'marial'/‘talasónima' de los mares (p. ej. Mediterranean fruit $f y$ ), 'corrental'/'reónima' de las corrientes marinas (p. ej. Chile current), 'sinusal'/'kolpónima' de las bahías (p. ej. Dublin bay prawn), 'fretal'/"portmónima' de los estrechos y canales (p. ej. Bristol Channel), 'fluvial'/'potamónima' de los ríos, riachuelos y arroyos (p. ej. Moselle wine o deónimos como carronade), 'lacunal'/'limnónima' de los lagos y lagunas (p. ej. Lake copper), 'fontanal' /'pegónima' de manantiales y fuentes (p. ej. geyser) y 'acuelapsal' /'cataractónima' de las cataratas y saltos de agua (p. ej. la película Niagara).

El Subgrupo Cuarto, la ubicación 'mundial', se reparte en cuatro Secciones: las concreciones 'continental'/'epirónima' ${ }^{17}$ (p. ej. europia o African migratory locust), 'subcontinental'/‘hipo-epirónima' (p. ej. indigo o Indian canarium), 'peninsularial'/'quersonesónima' (p. ej. labradorescence y labradorite) e 'insularial'/'nesónima' (p. ej. Manx shearwater).

El Subgrupo Quinto, la ubicación 'telustral', articula nada menos que dieciocho Secciones: las concreciones 'catenomontal'/'oreónima' de las cordilleras y las cadenas montañosas (p. ej. andesite), 'montal'/'lofónima' (p. ej. Mount Cook lily), 'vulcanal'/'hefestónima' (p. ej. vesuvianite), 'glaciaral'/'pagetónima' (p. ej. Athabasca entre los geónimos y Perito Moreno entre los antropónimos), 'precipital'/‘kremnónima' la asociada con barrancos (con el único ejemplo de jarosite), 'litoral'/‘actónima'

\footnotetext{
${ }^{17}$ Se excluyen el concepto anglosajón de America, pero también Australia porque pueden confundirse con el nombre del país.
} 
(p. ej. East coast fever), 'promontorial'/'acronteriónima' de los cabos (p. ej. Cape chrysolite), 'cervical'/'istmónima' de los istmos (p. ej. Isthmian script), 'fosal'/'baratrónima' de las fosas marinas (p. ej. Aleutian Trench o Aleutian Trough), 'espeluncal'/'espeliónima' de cuevas, grutas y minas (p. ej. bentonite), 'pedimontanal'/'podorónima' (p. ej. piedmontite), 'terralaltal'/'pediontónima' de las mesetas (p. ej. karst), 'vallisal'/'napónima' para valles (p. ej. en Neanderthal man), 'angustial'/'klisoriónima' (p. ej. desfiladeros como Las Termópilas en el nombre de clíper Thermopylae y puertos de montaña como el Khyber en el título de película King of the Khyber Rifles) 'pradal'/'limónima' para llanuras y praderas (p. ej. prairie falcon), 'ripuarial'/'octónima' para las cuencas de río (p. ej. glengarry), 'desertal'/‘eremiónima' (p. ej. Barstovian) y 'playal'/'egialónima' (p. ej. el deónimo daiquiri).

El Subgrupo Sexto, la ubicación 'vegetal', se reparte entre cuatro Secciones: las concreciones 'silval'/‘drimónima' de selvas y junglas (p. ej. Congolian forest), 'nemoral'/'hilónima' de los bosques (p. ej. Black Forest cake, que traduce literalmente, mediante adaptación semántica, el alemán Schwarzwaldkuchen), 'lucularial'/‘tamnónima' de bosquecillos, sotobosques y bosques arbustivos (p. ej. Ponderosa shrub forest) y 'paludial'/‘tifónima' de humedales, marismas, pantanos y manglares (p. ej. Everglades virus).

\section{FOCALIZACIÓN}

La distancia física entre el país de referencia del término o translema y la lengua y cultura término tiene suma importancia y, en el caso de los geónimos, supone tres grados definitorios. El primero tiene tres Subsecciones: 'primoterritorial'/'protóctono' si es del país y cultura de la lengua de origen (p. ej. California current), 'alteroterritorial'/'deuteróc tono' si lo es del país y cultura meta (Canary current) y 'alienoterritori al'/'heteróctono' si lo es de terceros (p. ej. Agulhas current), por tomar tres ejemplos paralelos.

\section{ACOTACIÓN}

La distancia física entre los países del contraste bilingüe se acota más todavía en tres Apartados: 'vecinal'/'ectóctono' si pertenece a un país fronterizo, (p. ej. el unimembre brie, el bimembre French vanilla o el plurimembre Belgian retort process para el Reino Unido, así como el bimembre Gulf Stream para los EUA), 'proximal'/"peráctono' si otro 
país se sitúa (o se ha situado en algún momento de la historia) enmedio, como Italia, Borgoña o Suiza por Francia o Alemania por los Países Bajos con respecto al Reino Unido (p. ej. Valpolicella o Variscan orogeny) y 'distal'/‘telóctono' si se sitúa más allá de un solo país entre medias (p. ej. Bohemian forest, Persian greyhound o Java man). Este difenciador puede ser de interés a la hora de establecer correlaciones de traducción, por la posible interferencia de un país culturalmente mediatizador e intermediario, 'vectigal' (Calvo, 2015: 315, 318, 325 s.), como vemos en rheinstone frente al antropónimo nominal strass en francés, en italiano y en otras lenguas por influencia del alemán o el Matterhorn, que será Cervino en español como en italiano.

\section{PARTICULARIZACIÓN}

También puede interesar que la distancia física sea común para el país de origen y el de meta. Hay cuatro Subapartados: las particularizaciones 'univecinal'/'mono-ectóctona' cuando solamente lo es de uno (p. ej. Belgian endive) frente a 'plurivecinal'/'poliectóctona' que sería el caso típico de Francia para el Reino Unido y España (p. ej. gallium); y los correlativos 'uniproximal'/'monoperáctona' cuando solamente lo es de una (p. ej. Ramillie (wig)) frente a 'pluriproximal'/'poliperáctona', de nuevo y típicamente, Alemania para ambos (p. ej. germanium). Este diferenciador y los dos siguientes son comunes a las tres Divisiones del Cuerpo de los geónimos.

\section{INDIVIDUACIÓN}

Especificando más todavía y por los mismo motivos que la particularización, podemos 'individuar' esa vecindad, determinando si lo es sólo de la lengua/cultura/país origen (NAC1) ${ }^{18}$ o sólo de la lengua/cultura/ país meta (NAC2). Así, tenemos las Entradas de las individuaciones 'primovecinal'/'proto-ectóctona' (p. ej. Continental quilt para el Reino Unido), 'segundovecinal'/‘deuterectóctona' (p. ej. Madeira cake para el Reino de España) y 'covecinal' 'sinectóctona' (p. ej. beaujolais para ambos). A ellos hay que añadir sus correlatos: 'primoproximal'/"protoperáctono' (como la película Amsterdammed) y 'biproximal'/‘diperáctono' (p. ej. Burgundian cadence o Würm).

\footnotetext{
${ }^{18}$ NAC es acrónimo de Nación y Cultura, siendo el número arábigo $(1,2,3)$ el que indentifica país/cultura de origen, meta o terceros.
} 


\section{VEHICULACIÓN}

Dentro del Cuerpo de los Geónimos, la Subentrada que llamamamos 'vehiculación' solamente se da en la División de los geónimos estatales y aprecia si el término se ha recibido por intermediación de una tercera lengua y/o cultura (NAC3). Esta será, típicamente, el francés, dentro de la Europa occidental, gracias a su posición geográfica y a su tradición cultural, hegemónica en la Edad Moderna. Hablamos de la Subentrada de vehiculación 'terciolingual'/'tritoglotónima'19. Del total de diez ejemplos, seis tienen que ver con el edilecto de la alimentación y el culino-/cucinolecto de la cocina/gastronomía (Calvo, 2014a: 46-52), entre ellos los galicismos ingleses hollandaise sauce frente al neeerlandés Hollandaisesaus, pero también mayonnaise frente a mahonesa, e incluyendo un madrilène $e^{20}$; un ejemplo es un animal (spaniel), uno un baile (carmagnole), uno un tipo de automóvil (berline) $\mathrm{y}$, finalmente, hay un perfume (Cologne water), donde el nombre de la ciudad, el geónimo 'civital'/'politónimo', está mediatizado por el francés.

Una variante específica dentro de la División de los geónimos estatales $-\mathrm{y}$ de un par de ejemplos de guerras del ámbito germánico entre los geónimos colegiales- es la Entrada de vehiculación 'equolingual'/'homoglotónima', donde el término es común a la lengua de origen pero no a la variedad nacional y a su tradición cultural específica. Por ejemplo, los estadounidenses llamarán a su guerra de liberación American Revolution, mientras que en Gran Bretaña se la conocerá como American War of Independence, siendo éste el término que se traduzca al castellano. De manera idéntica, tenemos ejemplos como football contra American football, French and Indian War frente al más común Seven Year's War y el deónimo derby en vez de bowler.

Como nota adicional, adviértase que el Apartado denominado 'tradición', compartido con el Cuerpo de los antropónimos, solamente se da en la División de los geónimos colegiales. Se denomina aquí 'suicultural'/ 'idiopedeusónima' y vale cuando el término refiere a un acontecimiento (típicamente bélico) que se ha librado entre países de una misma

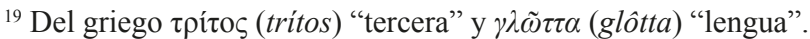

${ }^{20}$ Según la definición que ofrece el Collins English Dictionary se trataría de un consomé frío condimentado con salsa de tomate. Ni figura en el DLE hoy en día, ni mucho menos, a juzgar por los datos que ofrece el NTLLE, en 1907: la primera datación del galicismo en el Oxford English Dictionary.
} 
lengua y cultura, p. ej. Deutscher Krieg en alemán que, en español, se precisará como Guerra austro-prusiana.

\subsection{Los diferenciadores especificos antropónimos ejemplificados}

\section{APELACIÓN}

El primer diferenciador antropónimo específico es la División que establece el tipo de nombre (Calvo, 2014a: 34). Este puede ser 'prenominal' (p. ej. Roger), 'nominal' (p. ej. el deónimo de apellido colt), 'cognominal' (p. ej. el título hereditario de conde que pervive en el deónimo sandwich) o 'agnominal' (p. ej. el mote personal en el modificador quijotesco o el nombre de marca Bluetooth (mote del guerrero escandinavo Harald 'Bluetooth' Gormsson) ${ }^{21}$. La apelación agnominal se resuelve, a su vez, en dos tipos de 'consideración'.

\section{CONSIDERACIÓN}

La consideración 'comunal'/ 'metriónima' es la del mote corriente, como el personaje de la novela homónima Boule de suif. La segunda implica respeto y la denominamos 'respicial'/'sebastónima'22. Ésta última es un nodo que se ramificará en ocho Grupos de 'alusión'.

\section{ALUSIÓN.}

La alusión 'patricial'/'eugeniónima' refiere a los títulos de realeza y aristocracia (p. ej. Prince Rupert's drop, Queen Victoria waterlily o el pornoléctico británico Lady Jane que divulgara D. H. Lawrence). La alusión 'sacral'/ 'hagiónima' abarca las escalas de títulos de $\operatorname{santidad}^{23}$ (p. ej.

\footnotetext{
${ }^{21}$ En este caso, no acudimos al taxón doble porque la civilización griega no participaba de la tria nomina romana y, además, porque los grecismos posibles, onoma para el nombre y eponomia para el apelllido y el mote, se solaparían con otros ya en uso.

${ }^{22}$ Del latín respicere "tomar o tener en consideración".

${ }^{23}$ A la hora de traducir estos epónimos, incluso los nombres mismos de los santos, se pueden producir agregaciones 'lógicas', como Saint Louis y Saint Louis of France y substituciones culturales concretas, como San Juan Evangelista por Saint John the Divine. Pero, lo que más llama la atención es una coincidencia parcial con la $9^{\mathrm{a}}$ acepción de translate: to transfer (the body or the relics of a saint) from one resting place to another) que señala Collins English Dictionary - históricamente perteneciente al primer bloque (I, i a) en el Oxford English Dictionary con citas desde 1517- con diversos tipos de 'traslados geográficos'. Así tenemos, por ejemplo: 1) substitución del nombre propio geónimo de obitu (el lugar donde falleció) por el nombre propio geónimo de
} 
coquille Saint Jacques o deónimos como sanjuanada y santabárbara). La alusión 'curial'/'sinedrinónima' incluye los tratamientos eclesiásticos y de órdenes religiosas (p. ej. el zoónimo Père David's deer, la obra L'abbé C. o la película Two mules for Sister Sara). La alusión 'gradual'/ 'taxiónima' es la de la graduación militar (p. ej. en la obra Leutnant Gustl o la película Major Dundee). La alusión 'intelectual'/‘dianoyónima' lo es a un título académico (p. ej. la obra Professor Unrath, la película Das Cabinet des Dr. Caligari o la marca registrada Dr. Oetker). La alusión 'ministerial'/'demiurgiónima' lo es a un rango funcionarial administrativo o judicial (p. ej. la obra El alcalde de Zalamea o la película Judge Priest), La alusión 'societal'/'coinoniónima' refiere a un título de tratamiento social (p. ej. la obra Doña Bárbara, la película They call me Mister Tibbs o la marca registrada La Veuve Cliquot). Finalmente, la alusión 'parental'/'singenesónima' recoge los apelativos de respeto propios de la familia, incluso en sentido traslaticio (p. ej. la obra Le père Goriot, la película Whatever happened to Aunt Alice? o nombres de marcas como Aunt Jemima o Tio Pepe).

\section{EXTENSIÓN}

El Subgrupo de extensión tiene cuatro posibilidades: 'acrónimo' (p. ej. acrónimos propiamente dichos como $N S U$ (< Neckarsulm) o G. spot y apocópes como Pap smear o gal unit), 'hipocorístico' (p. ej. la obra Kim, la marioneta Kasperle alemana o el deónimo robin), 'pleno' ( $\mathrm{p}$. ej. la obra Parzival o el bimembre Dorothy bag) y 'múltiple' (p. ej. el zoónimo plurimembre Dolly Varden trout).

\section{ARTICULACIÓN}

Hay cinco tipos dentro de esta Sección. La 'binal'/‘diónima' es la articulación de los nombres propios, los epónimos o los deónimos dobles, no unidos por conjunción ni por guión y consistentes, típicamente, en un nombre de pila más un apellido (p. ej. la obra Hedda Gabler o la marca

humo (el lugar donde reposan sus restos), como en Saint Nicholas of Myra y San Nicolás de Bari; 2) substitución del nombre propio geónimo de ortu (el lugar donde nació) por el nombre propio geónimo de obitu (el lugar donde falleció), como Santo António de Lisboa y San Antonio de Padua; 3) substitución del nombre propio geónimo de ope (el lugar donde llevó a cabo (la mayor o mas importante parte de) su obra) por el nombre propio geónimo de obitu (el lugar donde falleció), como Saint Romanus of Casarea y San Román de Antioquía. 
de automóviles Mercedes Benz). La 'conjuncional'/‘anfiónima' es la de los epónimos o deónimos unidos por una conjunción copulativa, como Law of Charles and Gay Lussac o por \& como Villeroy \& Boch). La 'preposicional'/'protesiónima' e3s la de las articuladas mediante preposición (como en Tower of London test). La 'alternal'/'hipalelónima' es la de los unidos por una conjunción disyuntiva, (p. ej. la obra Ada or ardour, el cuadro Le Golfe de Saint-Tropez, ou La Ferme à l'aire, la ópera Le nozze di Figaro, o sia La folle giornata o la película Palermo oder Wolfsburg). El nodo 'yugal' de los que están unidos mediante un guión se subdividirá enseguida en dos tipos de 'ligazón'.

\section{LIGAZÓN}

La Subsección del especificador antropónimo 'ligazón' tiene tres variedades. La 'iteracional'/'sicnónima' se desprende de la articulación 'binal' y se da cuando se repite el nombre (como las películas Alfredo, Alfredo o Rachel, Rachel). De la articulación 'yugal' se derivan dos: la ligazón 'biyugal'/'dizigónima cuando dos nombres van unidos por guión (p. ej. Epstein-Barr virus o la marca de coches Hispano-Suiza) y la ligazón 'triyugal'/'trezigónima' cuando son tres los nombres unidos por guión (p. ej. Benedict-Hopkins-Cole reagent).

\section{TRADICIÓN}

El Apartado denominado 'tradición,' el último específico de los antropónimos, distingue la pertenencia cultural. El término puede ser: a) 'pri mocultural'/'protopedeusónimo' cuando pertenece a la cultura de la lengua de origen (p. ej. bobby), b) 'alterocultural'/‘deuteropedeusónimo' si pertenece, directa o indirectamente, a la cultura de la lengua término (p. ej. el español en matico ( $<$ Mateo), stevia $(<$ Esteve) y el bimembre Malaspina glacier (< Alejandro Malaspina), c) 'alienocultural'/ 'heteropedeusónimo' si no pertenece ni a la cultura de la lengua de origen ni a la de la lengua término ( $\mathrm{p}$. ej. los unimembres pierrot y seaborgium o el bimembre tournedos Rossini), d) 'patrimonicultural'/'kleronomiope deusónimo' si corresponde a una cultura heredada en común (p. ej. los fitónimos St. John's wort o hebe), e) 'bicultural'/‘dipedeusónimo' cuando deriva de dos lenguas y culturas distintas entre sí (p. ej. Williams Bon Chrétien pear, Fermi-Dirac statistics o el nombre de la empresa británico-neerlandesa Unilever) y f) 'controversial'/'anfisbetesimó nimo' cuando es de origen culturalmente disputado (p. ej. franklin en 
inglés frente a statcoulomb en francés o Graves'disease en inglés frente a Basedowsche Krankheit en alemán).

\subsection{Los diferenciadores especificos ctisónimos}

\section{PRODUCCIÓN}

El primer diferenciador específico del Cuerpo subordinado de los Ctisónimos, la División del tipo de producción, distingue tres variantes: La 'fabral'/'tecnónima' es la de la industria pesada, siderúrgica, química y extractiva, como el nominal Thyssen, el geónimo Rio Tinto Company Limited, el acrónimo y geónimo parcial REPSOL (Re(finería de) $P$ (etróleos de Escombreras) + sol), el geónimo Ciba (< Gesellschaft für) C(hemische) I(ndustrie) Ba(sel)) o el antropónimo nominal Pfizer. La 'comodital'/'crematónima' es de la industria ligera como Meissen o Texas Instruments entre los geónimos y la prenominal Napoléon o la nominal acrónima Mattel (Matt(son) + El(liot) entre los antropónimos. Y la 'creacional'/'ergónima' es la de las obras del intelecto, arquitectónicas y artísticas. Todas ellas se ejemplifican más adelante.

\section{CORPORACIÓN}

Dado el carácter híbrido de los ctisónimos, la siguiente especificación es un simple nodo que los articula en tres Subdivisiones: la corporación 'ordinarial'/‘coinotetónima' (nombre de productos o de marcas que no son ni geónimos ni antropónimos, como Bandaid o Cyclostyle), la corporación 'geónima' (p. ej. e-bay derivado de East bay de San Francisco o el deónimo landau) y la corporación 'antropónima' (p. ej. el biyugal Rolls-Royce).

\section{SECTORIZACIÓN}

La producción 'fabral' da lugar al Grupo de la sectorización 'industrial'/'ergasónima', la de los nombres de maquinaria y de compañías de la industria pesada, como el acrónimo $3 M(<$ Minnesota, Mining \& Manufacturing) o el nominal Henkel.

La producción 'comodital' da lugar al Grupo de la sectorización 'manufactural'/'quirotecnónima' de productos de la industria ligera, como el acrónimo $S A B A$ ( $<$ Schwarzwälder Apparate-Bau-Anstalt), de la manufactura (p. ej. Steinway \& Sons) o de la artesanía (p. ej. Sargadelos). 
La producción 'creacional' se multiplica por cuatro Grupos: la sectorización 'literal'/'gramaticónima' de los tres géneros literarios (épico, lírico y dramático), la sectorización 'edificatorial'/‘arquitectóni ma' de los nombres relacionados con la arquitectura, la sectorización 'figural'/‘iconónima' con los nombres de obras de arte plásticas y la sectorización 'interpretacional'/ 'hermenónima' para las artes del teatro, la música instrumental, el baile y el canto, todo ellas con ejemplos que se presentan mas adelante.

\section{VECCIÓN}

La especificación denominada 'vección' se desprende la sectorizaciones anteriores y se resuelve en doce Subgrupos.

La sectorización 'industrial' resultará en la vección 'transvecciona 1'/'diacomidéonima', con los nombres de medios de transporte de uso civil o militar como Toyota, o Lockheed (C-130) Hercules.

La sectorización 'manufactural' se trifurca: la vección 'utensilial'/'escrevostónima' (p. ej. el acrónimo Rowenta $((<$ Ro(bert) We(i)nt(r)a(ud)), el nominal pleno Bic, el biyugal Hewlett-Packard o el bicultural Fujitsu (<Fu(rukawa) + Ji(mensu) es decir: Siemens)) $+T s \bar{u}($ shinki)) que ya no sigue subdividiéndose, la vección 'alimental'/'bromatónima' de la industria de la alimentación (p. ej. Unilever) y la vección 'vestimental'/‘estematónima' de la moda y la ropa en general (p. ej. Loewe).

La sectorización 'literal' se multiplicará por los tres género literarios: la vección 'narracional'/'epicónima' (p. ej. Der grüne Heinrich), la vección 'carminal'/ 'poeticónima' (p. ej. Os Luisiadas) y la vección 'comedial'/‘dramatónima' (p. ej. Los locos de Valencia).

La sectorización 'edificatorial' se resolverá en la vección 'artifactual'/'tecnimatónima': los nombres técnicos propios de la arquitectura, como Hollander, Mexican tile o English roof truss.

La sectorización 'figural' se subdividirá en tres ${ }^{24}$ : la vección 'pictorial'/'graficónima' (p. ej. el geónimo Guernica o el antropónimo La nascita di Venere), la vección 'escultural'/'glifónima' (p. ej. la geónima La Dama de Elche o la prenominal doble de Perseo con la testa di Medusa) y la vección 'mocional'/'kinetónima' de los títulos de obras

\footnotetext{
${ }^{24}$ Aquí se podría añadir uno que incluyera las artes decorativas y utilitarias: cerámica, porcelana, tapices, muebles, cristalería, joyería, herrería artística y similares.
} 
cinematográficas, desde L'arrivée d'un train en gare de La Ciotat o Escamotage d'une dame chez Robert Houdin, por citar uno geónimo y uno antropónimo en los arranques del séptimo arte.

La sectorización 'interpretacional' se divide en dos vecciones: la 'teatral'/timelónima' (p. ej. Italian curtain) y la 'musical'/ 'eufonónima', nodo que se bifurcará inmediatamente en dos presentaciones.

\section{PRESENTACIÓN}

La especificación denominada 'presentación' consta de once Secciones.

La 'transveccional' se trifurca en tres 'presentaciones': la 'plaustral'/'amaxónima' de vehículos de transporte terrestre civil o militar (p. ej. el tren Flying Scotsman o la compañía francesa de vehículos acorazados y carros de combate $A M X(<$ A(telier de Construction d'Issy-les-)M(olineau)x), la 'vectorinaval'/'pistrónima' de buques (p. ej. el deónimo polacre/polacca) y la 'aeronaval'/'pterónima' de la navegación aérea (p. ej. el nombre amerindio del helicóptero de combate Black Hawk o la compañía aérea de transporte civil Lufthansa).

La vección 'vestimental' se recorta en tres 'presentaciones': la presentación 'petasal'/'pilónima' de los sombreros y complementos ( $\mathrm{p}$. ej. Bailey, Borsalino o Fedora), la 'vestimental'/'estematónima' de la ropa de vestir o deportiva (p. ej. Prada, Tommy Hilfiger o Lacoste) y la 'calceal'/'pedilónima' del calzado de vestir y deportivo (p. ej. Briganti, Ferragano, Manolo Blahnik o Adidas).

La vección 'alimental' se trifurca: la presentación 'cibal'/‘tenónima' de alimentos sólidos (p. ej. La Española o Kentucky Fried Chicken como geónimos y la prenominal Maria biscuits o la nominal Kellog's como antropónimos), la presentación 'potal'/‘enónima' de bebidas (p. ej. vichy, Solares o chianti como geónimos y Dom Perignon, Lavazza o Lipton como antropónimos) y la presentación 'vaporal'/'atmónima' de marcas de tabacos (como el deónimo geónimo habanos) y de cigarrillos ( $\mathrm{p}$. ej. los geónimos Pall Mall, Winston y Gauloises o los antropónimos Dunhill, Philip Morris o Lambert \& Butler).

La vección 'musical' se bifurca: la presentación 'instrumental'/'organónima' (p. ej. la unimembre L'arlesienne, la bimembre Brandenburgische Konzerte o la plurimembre Noches en los jardines de España entre los geónimos) y la presentación 'vocal'/ 'ftegmatónima', nodo que se trifurca enseguida. 


\section{DIFUSIÓN}

La presentación del nodo 'vocal' se trifurca en tres Subsecciones, laúltima de las cuales es también un nodo: la difusión 'saltatorial'/'balismónima' de los tipos de baile, la difusión 'canoral'/'odónima' (salmos, himnos, canto llano como el ambrosiano o el gregoriano, oratorios, cantatas, lieder y demás) y la difusión 'operal'/'liturgiónima' de los drammi per musica con sus descendientes y manifestaciones asociables (opera, opera buffa, opereta, singspiel o zarzuela), con los ejemplos que ahora veremos.

\section{REALIZACIÓN}

La Subsecciones comunes a las sectorizaciones 'figural' y 'narracional' son dos Apartados: la realización 'opificial'/‘dedalmatónima' de los títulos de obras y la 'artifactual'/tecnimatónima' que recoge los términos técnicos. Son realizaciones 'opificiales': Mansfield Park para la narracional, The Canterbury Tales para la carminal, Andorra para la comedial, Defensa de Cádiz contra los ingleses para la pictorial, la

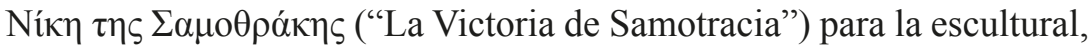
el deónimo morisca o Morris dance para la saltatorial, El concierto de Aranjuez para la instrumental, Israel in Egypt para la canoral y para la operal: Il barbiere di Siviglia para la geónima, Bastien und Bastienne para la antropónima o la zarzuela antropónima e hipocorística Katius$k a$. Realizaciones 'artifactuales' son el deónimo malapropism para la narracional, el deónimo celestina para la comedial, el geónimo Mersey beat para la instrumental, el unimembre Paeon para la carminal, el bimembre Celtic cross para la pictorial, el deónimo allemande para la saltatorial o el geónimo Geneva movement para la mocional.

\section{Una mínima apostilla sobre la traducción en nuestra taxonomía}

Hemos dicho al principio que nuestra taxonomía añade -'de oficio' por así decirlo- la traducción del término o translema, típicamente al castellano. Dado que nuestro corpus lo componen los epónimos y los deónimos de origen geónimo y antropónimo en los términos técnicos y los nombres de marcas, de obras intelectuales, arquitectónicas y artísticas, parecería obvio que el recurso traductológico obligado fuera el 'integral', el de la apropiación del original mediante la adopción o la adaptación (incluida la adaptación semántica de términos transparentes, 
como bird of paradise y ave del paraíso, por ejemplo) o, en su defecto, el recurso 'tropical', como la obra Confessions of an English opium eater y Confesiones de un inglés comedor de opio.

Con los nombres de marcas, la triangulación semántica, el recurso 'tropical', no es imposible: lo vemos en His Master's Voice que fue traducido al español ( $L a$ Voz de su Amo), y a las principales lenguas de Europa Occidental. Pero es lo inesperado, claro está, lo que resulta interesante.

La substitución de términos, motivada, entre otras por razones de tradición cultural ${ }^{25}$, es muy frecuente (Calvo, 2014a, 2014b, 2015, $2017 b, 2018)$ y, siendo común en algunos tipos de geónimos naturales, será abundante entre los geónimo estatales y los geónimos colegiales. Incluso, aunque sea más bien la excepción que la regla, se dará entre los nombres de marcas registradas y similares, ya sea por razones mercantiles de filiales, por voluntad política (SEAT (Sociedad Española de Automóviles de Turismo) frente a FIAT (Fabbrica Italiana Automobili Torino)), por limitaciones legales de propiedad de marcas o por no suscitar maltentendidos, como el Opel Corsa en vez del original Opel Nova. Vemos que también se da el trueque del nombre del juego de mesa Monopoly por el acrónimo antropónimo Palé ( $<P a(\mathrm{co}) L e(\mathrm{yva}))$; pero también se cambió Grundig por Inter, históricamente hablando y antes de acudir al recurso agregacional con el biyugal Inter-Grundig para acabar, al cabo del tiempo, en la adopción Grundig. Fuera de los epónimos puros, tenemos ejemplos como el del deónimo stetson y sombrero vaquero entre otros muchos de naturaleza parecida.

El recurso 'agregacional' suele tener carácter explicativo o glosarial y se da hasta entre los nombres de marcas, como acabamos de ver.

El recurso 'obvial' de supresión, el eclipsal parcial, sería el antitético del anterior si la traducción se produjera en el sentido inverso, pero también podría ser sinonímico de un recurso eclipsal parcial como ya hemos dicho, no omitiendo el término entero -como en hellraiser, Devon minnow o cape cod cottage- sino tan sólo una parte, como en Colorado potato beetle y escarabajo de la patata.

\footnotetext{
${ }^{25}$ Los ejemplos príncipe serían, en el caso de los geónimos, Aachen en alemán y Aixla-Chapelle en francés frente al español Aquisgrán o el italiano Aquisgrano, por ser deudoras ambas culturas del latín Aquisgranum y, entre los ejemplos antropónimos, la adopción ortográfica y adaptación fonetica Michelangelo del inglés frente a Michel Ange o Miguel Ángel.
} 
La situación e hipotética solución de los translemas netamente eclipsales ya han sido comentadas.

\section{Bibliografía}

\subsection{Bibliografia utilizada}

Alcaraz Varó, Enrique. 2000. El inglés profesional y académico. Madrid: Alianza Editorial (Materiales / Filología y Lingüística).

Cabré, María Teresa. 1993. La terminología: teoría, metodología, aplicaciones. (Prólogo de J. C. Sager). Barcelona: Editorial Antártida / Empúries.

Calvo García de Leonardo, Juan José. 2014a. BSOs, subtitulados, trampantojos y saborizantes: la eponimia en los textos de turismo, El lenguaje del turismo y la publicidad: terminología y traducción. ePraxis (plataforma del grupo editorial Wolter Kluwer España, S.A.), 31-57.

Calvo García de Leonardo, Juan José. 2014b. ‘CCanal anglais?, ¿Spanish omelette?, ¿Pasta italiana e Italian pasta?’ La geografía física y humana patente como escolio o escollo en traducción. En Vargas Sierra, Chelo. (ed.) TIC, trabajo colaborativo e interacción en Terminología y Traducción. Granada: Editorial Comares (Colección Interlingua 132), $317-$ 330.

Calvo García de Leonardo, Juan José. 2015. ¿DOC? La toponimia y la deonimia francesas, en la lengua y en el lenguaje, para el Hexágono y para los países limítrofes. En Colón, Germà; Kremer, Dieter \& Casanova Emili (eds.) Toponímia Romànica (Quaderns de Filologia. Estudis Lingüístics XX). Valencia: Facultat de Filologia, Traducció i Comunicació, Universitat de Valencia, 313-336.

Calvo García de Leonardo, Juan José. 2017a. Etumos Apistos, “Truly Doubtful": Confounding Etyma in Scientific Nomenclature, EPiC Series in Language and Linguistics 2: 354-365. https://easychair.org/ publications/paper/M5z. doi: https://doi.org/10.29007/lkss

Calvo García de Leonardo, Juan José. 2017b. El trueque de los bienes raíces: la substitución terminológica de nombres propios en botánica. En CandelMora, Miguel-Ángel \& Vargas-Sierra, Chelo (eds.) Temas actuales de terminología y estudios sobre el léxico. Granada: Editorial Comares (Colección Interlingua, 172), 69-98.

Calvo García de Leonardo, Juan José. 2018. Señuelos 'geónimos' en la eponimia y la deonimia científica y su tratamiento traductológico. III Congreso Internacional Ciencia y traducción: puentes interdisciplinares y traducción del conocimiento científico. Córdoba, 11-13 de abril. 
Fluck, Hans Rüdiger. 1976. Fachsprachen. Einführung und Bibliographie. Múnich: Francke Verlag GmbH.

Roelke, Thorsten. 1999. Fachsprachen. Berlín: Erich Schmidt Verlag. Roganova, Zoja E. 1971. Perevod s russkogo jazyka na nemeckiy. (Posobie na teorii perevoda dlja institutov i fakultetov inostrannyh jazykov) ("Traducción del ruso al alemán. (Manual de teoría de la traducción para los Institutos y Facultades de lenguas extranjeras)"). Moscú: Escuela Superior.

Santoyo, Julio César. 1986. A propósito del término TRANSLEMA. En Actas del I congreso nacional de AESLA. Murcia, 14-17 de abril de 1983. Madrid: AESLA-Sgel, 255-265.

Vidal Claramonte, M. ${ }^{a}$ Carmen África. 1995. Traducción, Manipulación, Desconstrucción. Salamanca: Ediciones del Colegio de España (Biblioteca Filológica).

5.2 Referencias lexicográficas usadas para la confección del corpus

\subsubsection{Referencias impresas}

Aguilar, Carlos. 2014. Guía del cine. (5. ${ }^{\text {a }}$ edición corregida y aumentada). Madrid: Cátedra (Signo e Imagen).

Beatty, William K. 1999. Stedman bilingüe. Diccionario de ciencias médicas. Inglés-español Español-Inglés (1. ${ }^{\mathrm{a}}$ edición, 2. ${ }^{\mathrm{a}}$ reimpresión 2004). Buenos Aires / Bogotá / Caracas / Madrid / México / São Paulo: Editorial médica Panamericana.

Beigbeder Atienza, Federico. [1988] 1997 (inglés-español) y [1987] 2002. (español-inglés). Diccionario politécnico de las lenguas española e inglesa (2 vols.). Madrid: Ediciones Díaz de Santos.

Boxall, Peter \& Mainer, José Carlos. 2006. 1001 libros que hay que leer antes de morir. Relatos e historias de todos los tiempos. Barcelona: Grijalbo.

Collins diccionario español-inglés English-Spanish. Edición completamente nueva para el siglo XXI. 2000. Glasgow / Barcelona: Harper Collins Publishers / Grijalbo Mondadori.

Collins English dictionary (21st century edition). 2000. Glasgow: Harper Collins Publishers.

Casares Sánchez, Julio. 2013. Diccionario ideológico de la lengua española. Madrid: Gredos.

Corbeil, Jean Claude \& Archambault, Ariane. 2004. (primera reimpresión). Diccionario visual. Español / Inglés / Francés / Alemán / Italiano. Montréal: Larousse. 
Corominas Vigneaux, Joan. 1955-1957. Diccionario crítico-etimológico de la lengua castellana (4 vols.). Madrid: Gredos.

González Casado, Pedro. 2000. Diccionario AKAL de términos musicales. Español-Inglés Inglés-Español. Madrid: Akal.

Miguel, Raimundo de \& Morante, El marqués de. 1889. Nuevo diccionario latino-español etimológico. Madrid: Agustín Jubera.

Diccionario de la lengua española (DRAE). 2014. (Edición del tricentenario. Vigésimo tercera edición. 1. ${ }^{a}$ tirada, octubre de 2014). Madrid: Real Academia Española.

Diccionario panhispánico de dudas. 2005. Real Academia Española. Asociación de Academias de la Lengua Española. Madrid: Santillana Ediciones Generales, S. L.

Lorenzo, Emilio. 1996. Anglicismos hispánicos. Madrid: Gredos.

Moliner Ruiz, María. 1975. Diccionario de uso del español. Madrid: Gredos.

Navarro Beltrán, Eliseo (ed.). 1992. Diccionario terminológico de ciencias médicas (DCTM) (Decimotercera edición). Barcelona: Elsevier Masson (Elsevier España, S. L.).

Onions, Charles Talbut; Friedrichsen, George Washington Salisbury \& Burchfield, Robert William (eds.). 1969. The Oxford dictionary of English etymology. Oxford: Oxford University Press.

Oxford English dictionary. 1971. The compact edition of the complete text reproduced micrographically (2 vols.) (1984, 23 $3^{\text {rd }}$ printing). Oxford: University Press. Complete text reproduced micrographically. Vol. 3 (1987). A supplement to The Oxford English Dictionary Volumes I-IV. Oxford: At the Clarendon Press. http://www.oed.com/

Oxford-Duden pictorial English and Spanish dictionary, The. [1979] 1995. (2." ed.). Oxford: Clarendon Press.

Rodríguez González, Félix (dir.) \& Lillo Buades, Antonio. 1997. Nuevo diccionario de anglicismos. Madrid: Gredos.

Sánchez Benedito, Francisco. 1998. A semi-bilingual dictionary of euphemisms and dysphemisms in English erotica. Granada: Editorial Comares (Interlingua, 6).

Schneider, Stephen Jay. 2004. 1001 películas que hay que ver antes de morir. Barcelona: Grijalbo.

Skeat, Walter William. 1879-1882. An etymological dictionary of the English Language. Oxford. (reimpresión 1988). Clarendon Press

Sebastián Yarza, Florencio I. (coord.). 1964. Diccionario griego-español. Barcelona: Editorial Ramón Sopena. 


\subsubsection{Referencias en línea}

El listado terminológico del International Council of Onomastic Sciences (ICOS) está disponible en línea en: http:/docslide.us/documents/ icos-terminology-list-english-2011-081.html (consultado 28-01-2016).

El contraste multilingüe de algunos nombres propios y términos técnicos se ha ido comprobando en: https://www.wikipedia.org/.

Nuevo tesoro lexicográfico de la lengua española. buscon.rae.es/ntlle/ SrvltGUILoginNtlle.

Woodhouse, Sidney Chawner. 1910. English-Greek Dictionary. A vocabulary of the Attic language. Londres: George Routledge \& Sons Ltd. https:// www.lib.uchicago.edu/efts/Woodhouse/. 